\title{
Technology of training future seafarers to work in a multinational ship crew
}

\author{
Marina Nikonorova ${ }^{1, *}$ and Liliy Kemalova ${ }^{1}$ \\ ${ }^{1}$ Kerch State Marine Technological University, 298309, Crimea, Kerch, Russia
}

\begin{abstract}
The article deals with the issues of the need of professional training of cadets to work in a multinational ship's crew. The substantiation of the need to develop a technology for training future seafarers to be ready for joint work with representatives of various ethnic groups is presented. The characteristics of the components of socio-psychological technology are given.
\end{abstract}

\section{Introduction}

The sphere of communication and human interaction in modern society is very extensive. Each person becomes part of a complex system of relations: interpersonal, professional, labour, religious, etc. Nowadays, no one is surprised by the existence of multiethnic labor collectives. Multinational ship crews are pretty common today. Therefore, the implementation of a competency-based approach should ensure the development of professionally important qualities of future seafarers, allowing them to become real professionals. Much attention should be paid to the development of leadership qualities, knowledge, skills and abilities for personal growth. The possibilities of team interaction, tolerant perception of social and cultural differences should be taken into account. Future seafarers should learn how to select and apply methods of motivating work appropriate to the situation and personal characteristics of crew members, predict the consequences of intercultural contacts for groups and individuals and organize team interaction to achieve the assigned tasks, taking into account the ethnic characteristics of the crew members.

Employment of foreigners in ship crews it is quite frequent. However, there are some difficulties experienced by the officers working in such crews. It includes various situations arising in the process of managing foreign personnel, namely rallying of diverse cultural and ethnic groups. These difficulties are not sufficiently detailed in Russian cross-cultural psychological research of management.

\section{Comparative analysis of approaches}

The ethical aspect is closely related to the balance between the various approaches to the evaluation in the organization, since the mental models of ethical behavior among employees of different nationalities may differ. Moreover, the understanding of ethical

\footnotetext{
*Corresponding author: marianna_iv@rambler.ru
} 
management may also differ among different employees, among the crew and among the organization as a whole.

The work and management of a multinational ship crew has its own specific characteristics. It should be taken into account that multinational groups are characterized by intensive inter-ethnic communication and as a rule form small groups on an ethnoterritorial basis.

Often, when a sailor becomes part of a multinational crew, it turns out that he is not yet ready to communicate with representatives of a particular nationality. In such situations, communication barriers, stereotypical attitudes and beliefs appear. This causes mutual distrust, tension and some other psychological difficulties [2].

The lack of specialized training among managers is the main reason for the serious difficulties in managing a multinational crew. As pointed out by E.Yu. Gorokhova. “... only four to five years after the start of practical work, the managers of work collectives acquire sufficient knowledge of the national and socio-psychological characteristics of those people they have to work with, and only then stable skills and abilities of regulating inter-ethnic interaction and relationships are developed" [3].

Luhmann $\mathrm{N}$. called the interaction of the individual and the social system "interpenetration" [2]. So, when representatives of different cultures interact, there is a mutual exchange of information, emotional states, knowledge, etc. Thus, the sooner this process of interchange takes place, the easier it will be for the crew members to adapt to the new conditions of life and activity, and, consequently, to cope with the culture shock.

Gorokhova E.Yu. indicates: “... that for the effective management of a multinational team of an organization it should taken into account its specific characteristics, namely, the static and dynamic aspects of the team's system, as well as the ethical features of managing such a team. It can be assumed that it is the social technology of knowledge management that helps to take them into account and focus on the possibilities and mitigate the shortcomings" [2].

It is critical to study intercultural adaptation. In a broad sense it is understood as a complex process, thanks to which a person achieves conformity (consistency) with a new cultural environment, as well as the result of this process. Usually, the internal and external sides of adaptation are distinguished. The internal side is expressed in the sense of satisfaction and wellness, and the external one in the participation of the individual in the social and cultural life of the new group.

The term "culture shock" was introduced by the American anthropologist K. Oberg. He assumed that entering a new culture is accompanied by unpleasant feelings, for example, loss of friends or status, exclusion, surprise and discomfort when realizing differences between cultures, as well as confusion in value orientations, social and personal identity.

Symptoms of culture shock are very diverse. It can be constant anxiety about the quality of food or potable water, about whether the dishes and bed linen are clean, fear of physical contact with other people, general anxiety, irritability, lack of self-confidence, insomnia, feeling of exhaustion, alcohol and drug abuse, psychosomatic frustration, depression, and suicide attempts [3]. The feeling of loss of control over the situation, the feeling of one's own incompetence and failure to fulfill expectations can be expressed in fits of rage, aggression and hostility towards representatives of the host country, which does not at all contribute to harmonious interpersonal relations.

\section{Technologies for solving professional problems}

Ethno-psychological phenomena can be manifested both by the individuals and groups. Thus, it affects both the group dynamics of crews and the ship operations in general. To investigate these phenomena means to reveal the essential characteristics of the psyche of 
this or that ethnic group, their patterns and mechanisms of manifestation in work. Taking into account ethno-psychological factors is an important prerequisite for increasing the efficiency of management and organization of the work process [4-6].

First of all, the captain, mates and other officers should pay attention to the following:

1. Relationships between ethnic groups: features of communication, interaction both at work and in everyday life;

2. In a multinational crew, small groups are always formed based on ethnicity. Such groups are headed by an informal leader. Work with such groups should be aimed at identifying the motivational component of each microgroup. It is also necessary to focus attention on systematic work with the leaders of such groups.

3. Due to insufficient, superficial knowledge about the culture and traditions of representatives of other (not their own) ethnic groups, interpersonal and intergroup conflicts may arise.

4. When negative political and ideological issues arise in communication between representatives of different ethnic groups, ethnocentrism may appear. Moreover, it may then lead to nationalism.

When ethnic stereotypes appear in a ship's crew, representatives of various ethnic groups tend to defend and exaggerate their positive value determination among other communities. Groups choose and treat as absolute the characteristics that correspond to their positive social status, which looks higher than the status of other ethnic communities. The captain and mate of a multi-ethnic ship's crew need to isolate so-called national prejudices from the entire field of national stereotypes - inadequate and significantly distorting the reality of attitudes and stereotypes and challenge them.

The captain and officers of a multinational ship's crew have to be aware of their own national stereotypes, to get rid of national prejudices and to create a system of adaptation measures, the purpose of which is to teach the crew to work together.

For the professional management of a multinational ship's crew, officers should possess the following knowledge:

1. National psychological and other characteristics of microgroups in the crew (language, culture, traditions, etc.);

2. Their behavior, forms and actions in various ordinary situations of interpersonal relations, communication, interaction;

3. Stereotypical portrayals of people of certain groups by representatives of other nationalities;

4. Characteristic of national identity (it is useful to learn through consultations with specialists);

5. Needs, motives, value orientations;

6. Intellectual and cognitive components of national identity in individual and joint activities;

7. Facts indicating the existence of contradictions between the components of the national psychology of microgroups and the norms of business, political and interethnic interaction traditional for a given vessel.

The peculiarity of interaction between various micro-groups of a multinational ship's crew is influenced also by the culture (low-context or high-context) the crew members belong to. In high-context cultures, when transmitting information, people tend to pay more attention to the context of the message, to who and in what situation they are communicating. This feature is manifested in giving special significance to the form of the message, focusing on how to say rather than what.

Low-context cultures are characterized by a cognitive style of information exchange, in which significant requirements are imposed on fluency of speech, accuracy of using concepts and the consistency of the communicator's statements. In order to stand out within 
the group and "show off in society", representatives of such cultures strive to develop their speech skills.

High-context cultures are characterized by a greater differentiation of emotional categories in comparison with low-context cultures. It is reflected in the style of interpersonal relations. Attention to the context of messages is shown in the richness of linguistic means for expressing emotions, in the desire to convey all shades of feelings that arise between people and all fluctuations in the relationship between them. High-context cultures can significantly differ in the way of showing emotions during communication.

The more the dependence of communication on the situation is traced in culture, the more attention is paid in it to non-verbal behavior, i.e. facial expressions, gestures, touches, eye contact, spatial and temporal organization of communication. All cultures have developed gestures that have their own cognitive meaning, that is, they are able to independently convey a message, although they often accompany speech. Misunderstanding or misinterpreting non-verbal communication signs can cause communication barriers. Communication barriers are one of the reasons why intrapersonal, interpersonal, intragroup and intergroup conflicts arise in the crew. They can also lead to a decrease in the performance of commanders and other crew members. Moreover, such conflicts can affect interpersonal relationships, emotional state, degree of job satisfaction, etc. Therefore, the importance of prevention and dealing with communication barriers in a multinational ship's crew is obvious.

To identify the psychological characteristics of a person that affect the quality of communication and interaction in a multinational ship's crew, we conducted a pilot empirical study. The sample involved cadets working in multinational ship crews. The average age of cadets is 37.7 years. The number of respondents is 57 .

The study was carried out using the following methods:

- Questionnaire for measuring tolerance (Vladimir S. Magun)

- Diagnostics of the level of tolerance formation among students,

- Method of diagnostics of general communicative tolerance (V. Boyko).

Questionnaire for measuring tolerance (Vladimir S. Magun) - all questions of the methodology are aimed at identifying different attitudes. Therefore, like the vast majority of other ones, it measures, first of all, the tolerance of people verbal behavior. The questionnaire includes statements aimed at identifying different types of tolerance: tolerance towards representatives of other nations, people from other countries, representatives of other cultures; tolerance for other views, including the views and opinions of the minority; tolerance to the complexity and uncertainty of the surrounding world.

\section{Comparative analysis of research indicators}

Diagnostics of the level of tolerance formation among students - the questionnaire allows us to make a conclusion about the level of tolerance (or intolerance) formation among the respondents. Four such levels are conventionally distinguished: high and low levels of tolerance, as well as high and low levels of intolerance.

A high level of intolerance is expressed in a conscious refusal to recognize, accept and understand representatives of other cultures. This is manifested in a person's tendency to characterize cultural differences as deviations from a certain norm, as deviance. It is also can be seen in unwillingness to recognize the equal rights to existence of those who have a different physical appearance or who share different values.

A low level of intolerance is characterized by the fact that a person verbally recognizes the rights of others to cultural differences, declares the principle of equality of people regardless of their racial, national, religious affiliation, but at the same time experiences 
personal rejection of certain socio-cultural groups. A person tries to justify such a dissonance between the declared humanistic principles and the real manifestation of intolerance by the public opinion ("everyone thinks so"), immoral behavior allegedly characteristic of representatives of these groups ("they are all like that"), personal unsuccessful experience of interaction with them ("I met such people and I am sure that ...").

A low level of tolerance is determined by the recognition and acceptance of cultural pluralism, respect for different socio-cultural groups, but at the same time a person's tendency to share (often unconsciously) some cultural prejudices, to use stereotypes in relation to representatives of certain cultures.

A high level of tolerance is characterized by the following features. This includes the recognition of other cultures, the recognition of the right of people to a different way of life, the free expression of their views and values. It can also be the acceptance of other cultures, a positive attitude towards cultural differences, an increased susceptibility to any manifestations of cultural discrimination, the ability to find something useful and valuable for oneself in another culture.

The method of diagnostics of general communicative tolerance, proposed by V.V. Boyko, makes it possible to diagnose tolerant and intolerant attitudes of the personality, manifested in the process of communication. According to the author of the method, communicative tolerance or tolerance in communication is subdivided into situational, typological, professional and general. The level of situational tolerance is determined by a person's attitude to a specific communication partner and typological by the attitude to the collective type or group of people. Professional communicative tolerance manifests itself in a work environment, in interaction with those people with whom one has to deal with by the type of their activity. General communicative tolerance results from life experience, character traits, moral principles and largely predetermines other forms of communicative tolerance.

After calculating the indicators of tolerance or intolerance for each method, we calculated the average value and determined the levels of tolerance of the respondents.

The results are shown in Figure 1.

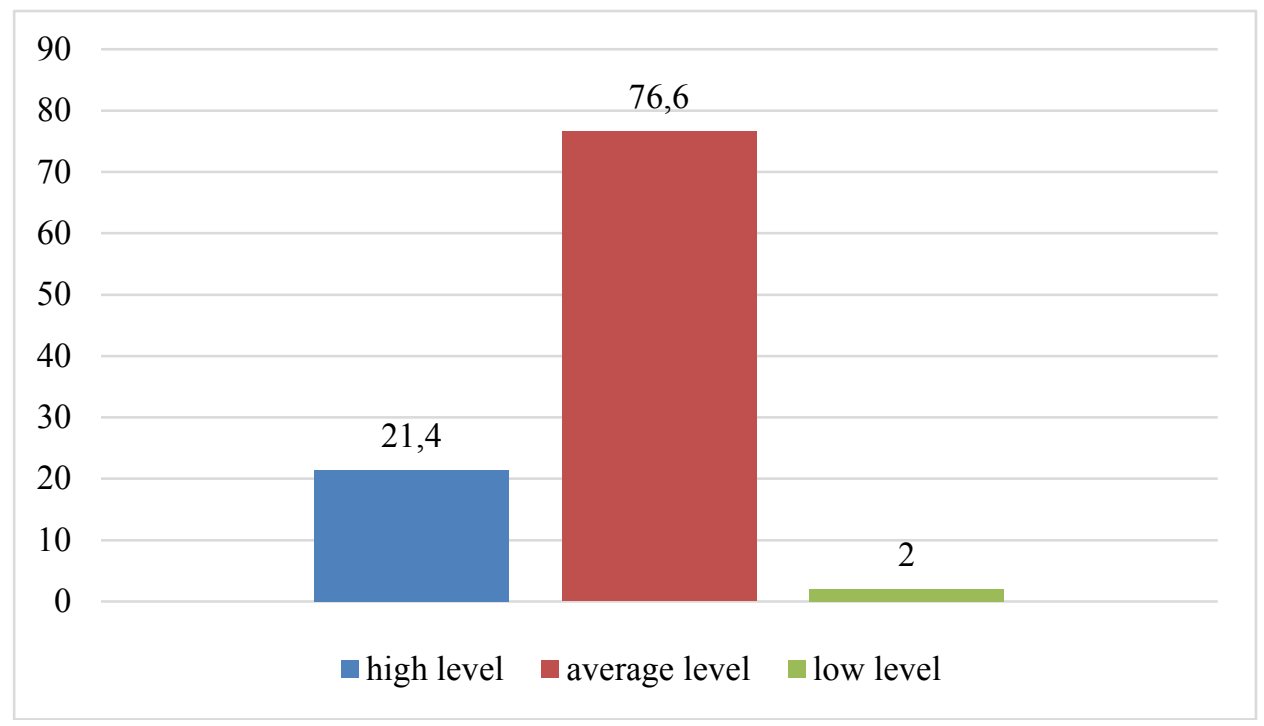

Fig. 1. Levels of tolerance of respondents. 
As can be seen, the majority of respondents showed an average level of tolerance. However, it is disturbing that still $2 \%$ of the respondents showed a low level. This may be an indication that these respondents will experience difficulties when working in a multinational crew. Taking into account the obtained high indicators according to the criterion of "low level of intolerance" $-35.7 \%$ of the respondents, it can be concluded that more than a third of the respondents are not ready to work in a multinational crew, as they experience rejection of certain socio-cultural groups.

Thus, there is no doubt that it is necessary to develop a technology for training cadets to work in a multinational ship's crew.

We believe that the technology should consist of three components:

1. Informational;

2. Diagnostic;

3. Correction- and development (formative).

The informational component suggests the definition of the essence of intercultural communication, the description of features of work in a multinational ship's crew, the analysis of socio-psychological phenomena arising from the interaction of representatives of different nationalities, the systematization of the main types of groups according to ethnicity, etc.);

Diagnostic component (analysis of the main criteria and indicators of the phenomenon under study, justification of the feasibility and application of diagnostic methods when assessing the level of tolerance, listening skills, the presence of ethnic stereotypes and attitudes, preparation of reports on the testing, etc.). The complex of practical methods of psychological diagnostics can be made up of the following methodology: tolerance test, paired samples test for metaphors and similes, conflict test, E. Bogardus's social distance scale, R. Likert's scale, The Twenty Statements Test: Who Am I?, the method of assigned qualities of D. Katz and K. Braly et al. [1].

Correction- and development (formative) component (a system of trainings, individual and group consultations, role-playing and business games aimed at the formation of ethnic tolerance, work with ethnic stereotypes and attitudes, reduction in the level of conflict, aggressiveness, listening and speaking skills, as well as the formation of teamwork skills).

\section{Conclusion}

It should be noted that when training cadets it is necessary to develop skills of working in a multinational ship crew as well as managing it. A multinational collective, as the researchers of the specifics of managing a multinational teams point out to, also requires special management.

To prevent negative situations in a multinational ship's crew, ship commanders, heads of departments, heads of practice need to pay attention to individual differences within the crew (language, gender, age, skills, experience, cultural and national characteristics). It is necessary to build relationships between crew members, emphasizing strengths of each other and create conditions for the favorable manifestation of national characteristics.

Thus, it is important to develop technology for training cadets to work in a multinational ship's crew. This stems from the peculiarities of the modern labor market in the maritime industry and the need to form knowledge, skills and abilities to work in such conditions.

The next step in the work on this topic will be the creation of "Technology for training cadets of Kerch State Marine Technological University to work in a multinational ship crew" and its further approbation. 


\section{References}

1. Z.F. Alistanova, Studying Ethnic Stereotypes: Approaches and Methodology, https://cyberleninka.ru/article/n/issledovanie-etnicheskih-stereotipov-podhody-imetody/viewer

2. L.I. Grosheva, Socio-cultural analysis of inter-national relations in organizations of closed type, https://elar.urfu.ru/bitstream/10995/59080/1/978-5-91256-4031_2018_023.pdf

3. E.Yu. Gorokhova, Specificity of management of multinational personnel of organizations, http://e-journal.spa.msu.ru/uploads/vestnik/2010/vipusk_24._sentjabr 2010_g./problemi_upravlenija_teorija_i_praktika/gorokhova.pdf

4. S.G. Chernyi, N.A. Logunova, and L.V. Aleksahina, IEEE International Conference "Quality Management, Transport and Information Security, Information Technologies" (IT\&QM\&IS) (St. Petersburg, Russia, 2018) doi: 10.1109/ITMQIS.2018.8524919

5. N. Logunova, L. Aleksahina, S. Chernyi, International Conference "Quality Management,Transport And Information Security, Information Technologies" (IT\&QM\&IS) (2017) doi: 10.1109/itmqis.2017.8085781

6. L. Kemalova, M. Nikonorova, E3S Web Of Conferences 110, 02002 (2019) doi: 10.1051/e3sconf/201911002002 